\title{
Purely endoscopic resection of a choroid plexus papilloma of the third ventricle: case report
}

\author{
Maria M. Santos, MD, and Mark M. Souweidane, MD \\ Department of Neurological Surgery, Weill Cornell Medical College; and Division of Neurological Surgery, Memorial Sloan \\ Kettering Cancer Center, New York, New York
}

\begin{abstract}
The authors report an illustrative case of a purely endoscopic surgical approach to successfully remove a solid choroid plexus papilloma of the third ventricle in an infant. A 10-week-old male infant first presented with transient episodes of forced downward gaze, divergent macrocephaly, a tense anterior fontanel, diastasis of the cranial sutures, and papilledema. Brain MRI revealed a small, multilobulated contrast-enhancing mass situated within the posterior third ventricle, with resultant obstructive hydrocephalus. A purely endoscopic removal of the tumor was performed through a single right frontal bur hole. Intraoperatively, a unique vascular tributary was recognized coming from the tela choroidea and was controlled with coagulation and sharp dissection. Postoperative MRI confirmed complete tumor removal, and the tumor was classified as a choroid plexus papilloma. There has been no evidence of tumor recurrence over 42 months of followup. With this case report the authors intended to show that endoscopic surgery can be an additional tool to consider when planning a choroid plexus tumor approach. It seems to be of particular interest in selected cases in which there are concerns about the patient's total blood volume, as in infants with potential hemorrhagic tumors and when it is possible to preoperatively identify a single vascular pedicle that can be approached early in the surgery.
\end{abstract}

http://thejns.org/doi/abs/10.3171/2014.12.PEDS14287

KEY WORDS choroid plexus papilloma; intraventricular endoscopy; infant; oncology

$C_{i}$ HOROID plexus papillomas (CPPs) are described as benign lesions with a potential cure rate of $100 \%$ if gross-total resection is achieved. ${ }^{3}$ In fact, there is no need for adjuvant therapy following a gross-total resection; however, the surgical removal of choroid plexus tumors is technically demanding because of their central location and hemorrhagic potential. The combination of their rich vascularization and their high incidence in young children makes their resection particularly challenging given the potential for massive intraoperative hemorrhage. Despite great advances in diagnostic imaging, microneurosurgery, interventional neuroradiology, and neuroanesthesia, the mortality rate directly related to intraoperative hemorrhagic shock has been reported to be as high as $12 \% .^{7}$ Because of these features, a purely endoscopic method of removal is considered to be inconceivable. Herein, we report the case of a purely endoscopic procedure to successfully remove a solid $\mathrm{CPP}$ of the third ventricle in an infant.

\section{Case Report}

Clinical Presentation and Imaging Studies

A 10-week-old male infant first presented with a 3-week history of transient episodes of downward gaze and divergent macrocephaly. On examination, he was alert, active, and hemodynamically stable and he had a forced downward gaze, a tense anterior fontanel, and diastasis of the cranial sutures. His head circumference was at the 95th percentile and had crossed 2 percentile ranks in a 2 -week period. There was papilledema on fundoscopic observation. Imaging studies revealed a multilobulated contrast-enhancing mass situated within the posterior third ventricle and measuring $2 \times 1.4 \times 1.7 \mathrm{~cm}$ with resultant obstructive hydrocephalus (Fig. 1). Magnetic resonance imaging of the spine was negative for metastatic disease. On high-resolution T2-weighted sequences, the majority of the tumor was distinct from the ependymal surface, giving the tumor mass a pedunculated morphology (Fig. 2).

ABBREVIATION CPP = choroid plexus papilloma.

SUBMITTED June 13, 2014. ACCEPTED December 19, 2014.

INCLUDE WHEN CITING Published online April 10, 2015; DOI: 10.3171/2014.12.PEDS14287.

DISCLOSURE The authors report no conflict of interest concerning the materials or methods used in this study or the findings specified in this paper. Dr. Souweidane is a consultant for Aesculap. 


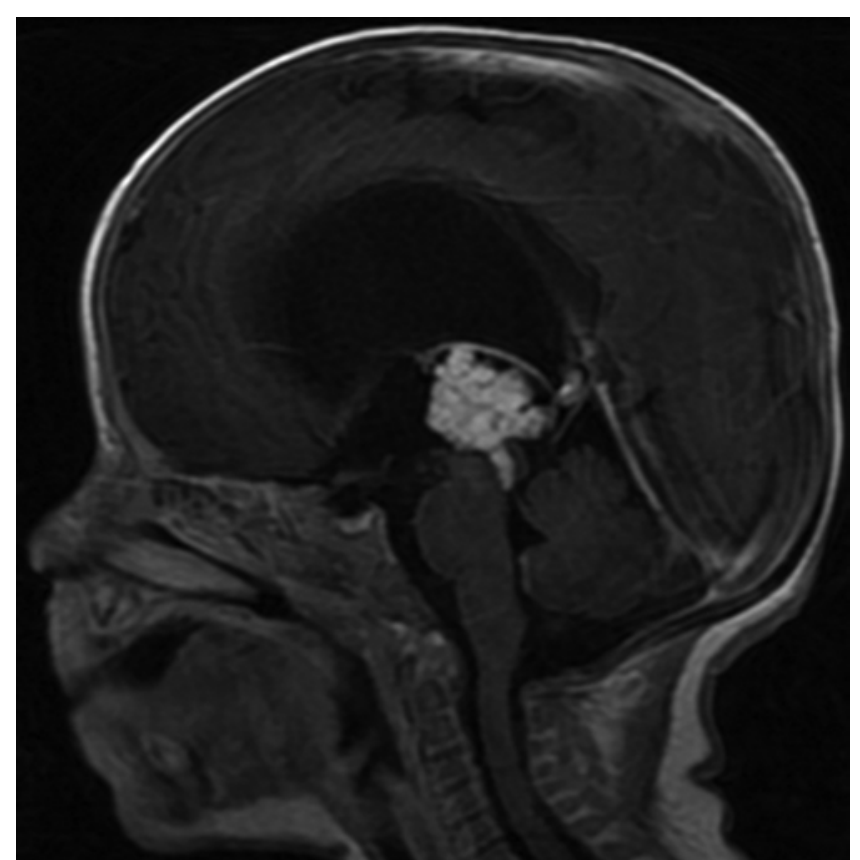

FIG. 1. Preoperative sagittal T1-weighted FLAIR MR image obtained postcontrast administration, showing a multilobulated mass in the posterior third ventricle.

Given the relatively small size of the tumor, the appearance of a dominant vascular pedicle, and the degree of ventriculomegaly, purely endoscopic removal of the tumor was proposed.

\section{Surgical Description}

After inducing general anesthesia, the patient was positioned supine on the operating room table with his head rested on a horseshoe head frame. No seizure prophylaxis or steroids were administered. Local anesthetic was applied, and a small curvilinear incision was created approximately $2.5 \mathrm{~cm}$ off the midline to the right and 4 $\mathrm{cm}$ up from the nasion. A single bur hole was placed, and the underlying dura mater was opened in a cruciate fashion avoiding coagulation of the dural leaflets. Underlying cortex was coagulated and incised. An endoscopic sheath with an obturator was then passed into the ventricular system. The endoscopic obturator was removed and replaced with a $30^{\circ}$ angled rigid endoscope (MINOP, Aesculap, B Braun Melsungen AG). Cerebrospinal fluid return was noted to be under mild to moderate pressure and clear. With inspection of the foramen of Monro, it was clearly evident that a large tumor consistent with a CPP was obstructing the third ventricle. There were no recognized lesions on the ependymal surface of the lateral ventricle. Generous coagulation was used on the anterior aspect of the tumor to decrease its size and offer enhanced visualization of the tumor interfaces. A vascular tributary was recognized coming from the tela choroidea. Bipolar cautery was used along the length of this vascular tributary. Sharp dissection was used to cut this pedicle, resulting in immediate mobilization of the mass within the third ventricle. To confirm that no other vascular supply existed, a $30^{\circ}$ angled endoscope was passed along all dimensions of

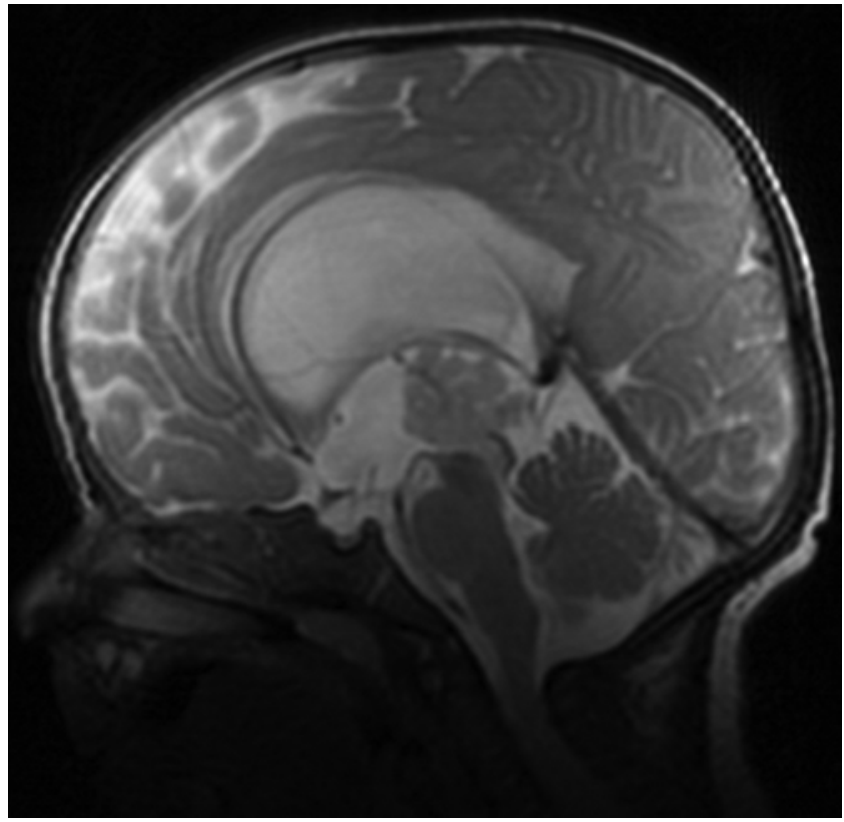

FIG. 2. Preoperative sagittal T2-weighted brain MR image showing a pedunculated morphology.

the tumor, utilizing bipolar cautery to dissect away from the hypothalami as well as the tela choroidea. Grasping forceps were used to mobilize the tumor from within the third ventricle up into the foramen of Monro and ultimately into the lateral ventricle. This was performed sequentially given the friable nature of the tumor. Given the mismatch between the maximal tumor dimension and the working portal, the tumor was removed piecemeal with the largest portions of tumor being extracted through the transcerebral endoscopic path. Endoscopic inspection confirmed no residual tumor or obstructing hematoma (Video 1).

VIDEO 1. Endoscopic resection of the third ventricle CPP through a right frontal approach. Copyright Mark M. Souweidane. Published with permission. Click here to view with Media Player. Click here to view with Quicktime.

The endoscope and sheath were removed, and the cortical incision was plugged with a hemostatic gelatin sponge and reinforced with fibrin sealant. The wound was then closed in a multilayered fashion. No externalized ventricular drain was used given the absence of hemorrhage and the repermeabilization of the ventricular system. Estimated blood loss was $10 \mathrm{ml}$. The duration of the surgery was approximately 1 hour 30 minutes.

\section{Postoperative Course and Pathology}

The patient made an uneventful recovery with complete resolution of signs of elevated intracranial pressure. Postoperative MRI confirmed total tumor removal patency of the sylvian aqueduct, a decrease in ventricular size, and small bilateral convexity hygromas (Fig. 3). The infant was discharged to home on postoperative Day 3 without any sign of pseudomeningocele or CSF leakage.

Pathology revealed papillary fronds of tissue lined by cuboidal to columnar epithelium. No atypia or mitotic activity was identified. The tumor was classified as a CPP, WHO Grade I. 


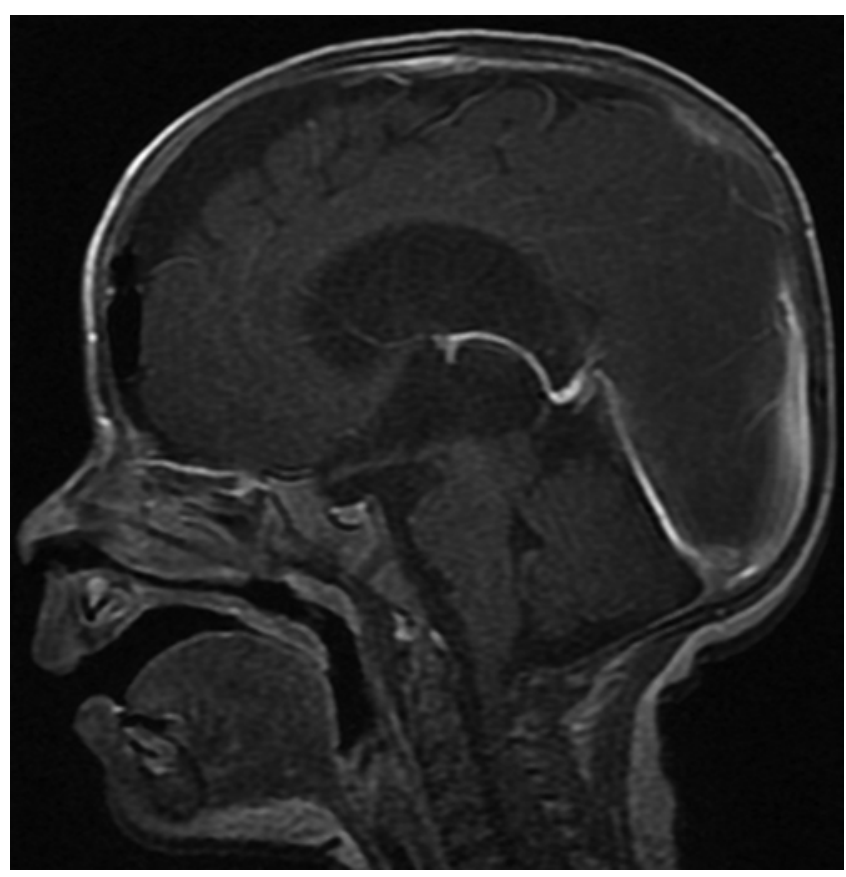

FIG. 3. Postoperative Day 1 sagittal T1-weighted MR image obtained postcontrast administration, showing no evidence of residual tumor.

On postoperative Day 7, the patient was readmitted with CSF leakage at the incision site and bacterial meningitis. The infection from Staphylococcus epidermidis was successfully treated with intravenous antibiotics. The patient underwent placement of a ventriculoperitoneal shunt for symptomatic hygromas and since then has been neurologically stable with a normal developmental assessment. There was no evidence of tumor recurrence over 42 months of follow-up.

\section{Discussion}

Intraventricular endoscopic surgery has an integral and expanding role in the management of patients with brain tumors. Established applications exist for tumor biopsy, concordant CSF diversion, tumor cyst decompression, and colloid cyst removal. A purely endoscopic technique for solid tumor removal has proved to be more technically challenging, has yet to gain widespread appeal, and thus has been infrequently reported. ${ }^{1,2,4-6,9-13}$ Often-cited limitations include inadequate bipolar cautery for hemostasis, a limited repertoire of surgical instruments for bimanual dissection, and the lack of adequate instrumentation designed for solid tissue tumor removal. ${ }^{8,10}$ The risk of CSF seeding of the tumor has never been proved to be higher with endoscopic approaches than with the microsurgical ones.

Limitations for solid tumor removal are varied, but hemostasis is paramount. Given this constraint, attempts at a purely endoscopic method of removing choroid plexus tumors are understandably scarce. Choroid plexus tumors are soft, vascularized lesions with a well-recognized potential for intraoperative hemorrhage. It is therefore understandable that these tumors have largely been omitted from endoscopic surgical series. The appeal in a minimal- ly invasive endoscopic approach, however, lies in the fact that the tumor would commonly have a defined pedicle to choroid interface. Successful removal would therefore hinge on the early recognition and control of that vascular tributary. Meng et al. previously reported endoscopic removal of a cystic CPP of the third ventricle in an 18-year-old patient. ${ }^{6}$ The currently featured case of purely endoscopic choroid plexus tumor removal is unique for 2 reasons. First, the young patient age and the increased potential for a disproportionate degree of blood loss present a greater risk profile than usual (estimated circulating blood volume in the patient was $360 \mathrm{ml}$ at the time of surgery). Second, in addition to the inherent challenge in the purely endoscopic removal of a solid intraventricular tumor, our case underscores the technical ability to endoscopically control a dominant vascularized tumor pedicle. In our case, focal attachment of solid tumor to the tela choroidea was visualized on high-resolution T2-weighted MRI. Cerebral arteriography may have contributed to the definition of the vascular supply and surgical strategy, but it was believed that the caliber of the involved vessels would prohibit any selective interventional procedure.

A previously published case report highlights the challenges associated with a purely endoscopic approach for these solid tumors. ${ }^{9}$ The mismatch between the papilloma and the endoscopic corridor in that case necessitated a concurrent microsurgical component, "a combined staged endoscopic and microsurgical approach."

Several techniques for tumor removal have been described. In 2002 Jho and Alfieri described the use of a rollable vinyl tube as a surgical corridor to remove third ventricle tumors. ${ }^{4}$ This technique has the advantage of a proportionate 1-cm-large working channel. In 2005 Souweidane and Luther described the use of a transparent 6-Fr endotracheal suction catheter to remove solid tumor tissue via a pulsed aspiration technique. ${ }^{13}$ These authors also described the use of neodymium:yttrium-aluminum-garnet lasers combined with suction to permit tumor ablation. In 2011 Dlouhy et al. described the use of a non-heat-generating, oscillating tissue cutting and removing instrument (NICO Myriad, NICO Corp.) that could be used through the working port of an endoscope. ${ }^{2}$ In 2013 Carr et al. described the adaptation of a urological stone basket (nitinol stone retrieval basket) to remove a neuroectodermal third ventricle tumor. ${ }^{1}$ The stone basket was small (allowing for its use through the working ports), flexible, and malleable and permitted the extirpation of free-floating lesions. In 2013 Selvanathan et al. described the use of a 3- $\mathrm{mm}$ ultrasonic aspirator to debulk an aqueductal glioneuronal tumor through an endoscopic approach. ${ }^{10}$

\section{Conclusions}

In this case report, we intended to show that endoscopic surgery can be an additional tool to consider when planning a choroid plexus tumor approach. It seems to be of particular interest in selected cases in which there are concerns about the patient's total blood volume, as in infants with potential hemorrhagic tumors, and when it is possible to preoperatively identify a single vascular pedicle that can be approached early in the surgery. 


\section{References}

1. Carr K, Zuckerman SL, Tomycz L, Pearson MM: Endoscopic removal of an intraventricular primitive neuroectodermal tumor: retrieval of a free-floating fragment using a urological basket retriever. J Neurosurg Pediatr 12:25-29, 2013

2. Dlouhy BJ, Dahdaleh NS, Greenlee JD: Emerging technology in intracranial neuroendoscopy: application of the NICO Myriad. Neurosurg Focus 30(4):E6, 2011

3. Ellenbogen RG, Winston KR, Kupsky WJ: Tumors of the choroid plexus in children. Neurosurgery 25:327-335, 1989

4. Jho HD, Alfieri A: Endoscopic removal of third ventricular tumors: a technical note. Minim Invasive Neurosurg 45:114-119, 2002

5. Luther N, Souweidane MM: Neuroendoscopic resection of posterior third ventricular ependymoma. Case report. Neurosurg Focus 18(6A):E3, 2005

6. Meng H, Feng H, Zhang L, Wang J: Endoscopic removal of a cystic choroid plexus papilloma of the third ventricle: a case report and review of the literature. Clin Neurol Neurosurg 113:582-585, 2011

7. Pencalet P, Sainte-Rose C, Lellouch-Tubiana A, Kalifa C, Brunelle F, Sgouros S, et al: Papillomas and carcinomas of the choroid plexus in children. J Neurosurg 88:521-528, 1998

8. Qiao L, Souweidane MM: Purely endoscopic removal of intraventricular brain tumors: a consensus opinion and update. Minim Invasive Neurosurg 54:149-154, 2011

9. Reddy D, Gunnarsson T, Scheinemann K, Provias JP, Singh SK: Combined staged endoscopic and microsurgical approach of a third ventricular choroid plexus papilloma in an infant. Minim Invasive Neurosurg 54:264-267, 2011

10. Selvanathan SK, Kumar R, Goodden J, Tyagi A, Chumas P:
Evolving instrumentation for endoscopic tumour removal of CNS tumours. Acta Neurochir (Wien) 155:135-138, 2013

11. Sood S, Hoeprich M, Ham SD: Pure endoscopic removal of pineal region tumors. Childs Nerv Syst 27:1489-1492, 2011

12. Souweidane MM: Endoscopic management of pediatric brain tumors. Neurosurg Focus 18(6A):E1, 2005

13. Souweidane MM, Luther N: Endoscopic resection of solid intraventricular brain tumors. J Neurosurg 105:271-278, 2006

\section{Author Contributions}

Conception and design: Souweidane. Acquisition of data: Santos. Analysis and interpretation of data: Santos. Drafting the article: Santos. Critically revising the article: Souweidane. Reviewed submitted version of manuscript: both authors.

\section{Supplemental Information Videos}

Video 1, Media Player. http://mfile.akamai.com/21490/wmv/ digitalwbc.download.akamai.com/21492/wm.digitalsource-naregional/peds14-287_video_1.asx.

Video 1, Quicktime. http://mfile.akamai.com/21488/mov/ digitalwbc.download.akamai.com/21492/qt.digitalsource-global/ peds14-287_video_1.mov.

\section{Correspondence}

Mark M. Souweidane, Department of Neurological Surgery, Weill Cornell Medical College, 525 E. 68th St., New York, NY 10021. email: mmsouwei@med.cornell.edu. 